\title{
Sustainable Building Life Cycle Design
}

\author{
Alexander Ginzburg, ${ }^{1, *}$ \\ ${ }^{1}$ Moscow State University of Civil Engineering, 129337 Yaroslavskoe sh. 26, Moscow, Russia
}

\begin{abstract}
The current building life cycle management system in the Russian Federation is a family of discrete subsystems that exist independently for different building life cycle stages. In this situation building reliability and sustainable functioning are out of the question. The implementation of a united information model (BIM-model) intended to describe building entire life cycle will allow to raise the sustainability, but this will happen only if goals and concerns of all participants of the project process are properly coordinated. An important figure of process sustainability is the organizational and technological reliability (OTR) that describes the possibility of a system to reach a goal. In case of building life cycle design, the economical efficiency of a building can be considered as the goal. The required technical, ecological, organizational, and other parameters form a complex of constraints that determine the area of allowable values for building functioning. In its broad meaning, OTR may be understood as the probability of receiving an economical effect based on the value of organizational and economical reliability (OER).
\end{abstract}

\section{Introduction}

Any physical object goes through different stages of existence. The "life cycle" term is intended to cover all these stages: from the concept design of a building to its removal and waste disposal. During its life cycle, a building can go as well through rebuilding, refurbishment, and even purpose changing.

At the concept design stage, the parameters of a future building are specified. The customer (Construction Investor) defines building expediency and specifies financing terms. If necessary, a detailed analysis and a product/service demand forecast are done. Their purpose is to ensure funding for the planned building.

The main concern for the investor is the conditions, the time of investment return and the profit margin from project realization. Even at this stage, i.e. before the beginning of any works serious contradictions of interests appear. The investors planning to sell the building immediately after construction will apply design requirements totally different from those of the investors planning to use the building by themselves. If a customer is not interested in a cost-saving and efficient use of a building, he will not order, for example, any energy and resource saving materials and technologies because they are usually more

\footnotetext{
* Corresponding author: ginav@mgsu.ru
} 
expensive and therefore disadvantageous at the design and construction stage. Such customer is not interested in the stage where energy saving costs begin to pay back.

This is only one of the most obvious examples. In fact, there are much more contradictions that affect the entire future life cycle of a building, particularly sustainability and duration.

Although as a rule people address all their complaints regarding buildings to builders, in fact, the builders build according to the project documentation developed by designers. What are designers' interests then? Here we should mention that the common practice in the Russian Federation is that design cost is calculated as a percent from construction and installation works. This means that the more expensive the construction object is, the better it is for the designer. Design firms are not interested at all in using innovative cost-saving materials, accelerated construction technologies etc. in their projects.

This can be well demonstrated by a comparative analysis of project designs made by design and construction entities, that is, by the companies doing both design and construction (in simple words, those who design for themselves) and usual design companies, that design for others. Even for similar buildings, the discrepancies are very significant.

\section{United informational base. BIM technologies}

The modern building life cycle management technologies are based on the creation and support of a building information model (BIM), the goal of which is to ensure the existence of a united informational base that would comprehensively describe a building.

Since the implementation of BIM technologies requires investment outlays, it can be considered as a realization of an investment project. This, in its turn, implies the necessity to justify the investment attractiveness of their implementation through a complex of assessment figures reflecting their economic efficiency and non-economic effects.

Here we have a question again: Economic efficiency for whom? The answer to this question determines not only the informational body of a BIM, but even the necessity of its application.

BIM technology application experience shows that their maximum pay off begins at the operational stage. As well, BIM is very effective at the stage of building removal and disposal, since the builders need information about the structure of the building, materials it was made of etc. As a rule, such analysis of a building takes a lot of time and money. But a building may serve for 100 years before it is removed and disposed of, while BIM requires investment at the design stage. Is the investor interested in it? He is, if he invests in a building intended for himself. If the building will be used by others, the modern businessmodels do not encourage the investor to spend extra money. Under current conditions in the Russian Federation, the investor as a rule cannot warrant a BIM by proving it to the buyer that though a building costs more, it will pay off faster.

Is BIM advantageous to design companies? That is, are design companies ready to apply BIM without additional funding (at their own cost)? As a matter of principle, BIM can give them additional advantage when they bid for tenders, they will be able to select and match a lot of building forming components more effectively, and to issue the required graphic and calculation documentation faster. Most Russian designers point out the effectiveness of BIM technologies when there is a need to reveal design internal mismatches and discrepancies (this especially applies to the design of complex utility systems), and note a significant time saving in case any modifications are needed. The software systems used for designing in BIM interface automatically replace one or another unit, assembly or material throughout the entire package of design documentation, which 
allows not only save time, but also avoid any engineering faults that often occur when high scale changes take place.

But we should keep in mind that to apply the BIM technology, a design company will have to purchase corresponding (and quite expensive) software and equipment, train their specialists to work with BIMs, and involve additional specialist managers into their staff to provide technical support to the system.

If assessed solely at the design stage, the effectiveness of the BIM technology does not look definitely justified. The increase of investments pay off is much more obvious when the generated model turns out to be of demand at the following stages of building life cycle.

If a BIM is intended to ensure building sustainability during its entire life cycle, then it should be filled with the figures that characterize the building at its different life cycle stages. Here we face the need to assess effectiveness again. For designers, the extension of mass data in a BIM in fact means the increase of overhead costs.

The modern BIMs do not imply that information on a building is entered into the united storage once and forever. In fact, the talk is about not one, but many databases interconnected by means of different interfaces and software systems. It is clear that during building lifetime, the data and the composition of the data change many times depending on the changing conditions, goals, etc. But practice shows that an originally correct data composition (composition of the data entered when a BIM was created at the design stage) significantly increases BIM effectiveness at the following stages.

In theory, BIM technologies can be applied, for example, from the construction stage if no BIM was created by designers. Having received design documentation in the electronic form the designers, a construction company in certain cases can export the received data into a software system intended for BIM based designing and use it for effective construction management, including coordination of works and materials, structures, and building products supplies in time.

Still, as well as in the case of designers, the construction company should take into account that application of BIM technologies in construction will imply significant material, time and organizational costs. The analysis of BIM application at the construction stage in the Russian Federation clearly shows that the implementation of these technologies is successful when the original BIM has been created at the design stage, and when designers entered the data taking into account it's future use at the construction stage. As a rule, this is possible in design and construction firms only, where designers and builders are united in one holding. In other cases, the investor should be seriously interested in such BIM and ready not only to pay for such close interaction of different participants of the process, but also organize it.

The next and the most important stage of a building life cycle is its use. As of today, a significant experience in the creation and use of smart buildings and even their conglomerates (micro-districts if not cities) has been accumulated. Technologies for monitoring the parameter that characterize building state and behavior have been developed, the mechanisms of human activity parameters adjustment and adaptation to different conditions have been proposed. However, practice shows that at least in the Russian Federation the building use stage is absolutely isolated from those information modelling achievements that are applied at the design and construction stage. In fact, there are no examples of BIM technology application at the stage of building use in the Russian Federation. Though, it is that very stage where companies might make use of all advantages of BIMs, because BIMs describe the history of building life cycle in details.

This can be partially explained by the fact that the wide application of BIM technologies is relatively young in the Russian Federation. So, the buildings for which BIMs were developed are either still being built, or have been built recently and their models have not been put into practice by the companies that use the buildings. It may be 
so, but the problem of economic interest in the creation and informational support of BIM technologies steps forward again. What can motivate a construction company to spend time and efforts on filling a BIM with data needed to someone else, not them?

\section{Content of BIM}

It should be mentioned that at present there is no complete and formalized mathematical formulation for building life cycle. This means that at different stages different isolated models are used. Different executors use different data sets, solve different problems and, by the way, not always correctly or successfully. Of course, all of these impacts building life cycle sustainability.

When speaking of BIMs, many people imply different informational content. The most spread opinion is that the main feature of a BIM design is its 3D representation. In fact, this achievement of BIM technologies is the most questionable one. The future experts are taught to read 2D drawings from the first course of the institute. A 3D picture is, of course, good when you do a presentation of your project to a non-professional customer, but it gives little in content respect.

The real advantage of BIM technologies emerges when 3D models are complemented with the technical parameters of structures, construction materials data, prices, load curves, delivery time, outsources' e-mail addresses, etc. At the use stage, all this information is as well complemented with the information on building components' technical state, repairs, upgrades, replacements, service life, expenses, and responsible persons and organizations. This is why today experts speak of N-D design, that is, of buildings described in general by $\mathrm{N}$-parameters needed for the analysis and mathematical formulation of its entire life cycle.

The more N-parameters are used, the more complex the mathematical model is. And this does not always imply that it is more effective. For example, we can collect a lot of data describing the current state of a building. The technological infrastructure of modern buildings and structures well allows to do it. But it is not always clear what should one do with these data. The modern construction science by no means always allows to interpret them correctly. A signal of temperature raising does not always indicate that a fire is spreading; and the information on cracks or micro-damages in separate structures is not always a sign of alarm. This is why the issue of reasonable sufficiency of BIM information should be discussed.

The main criteria for sufficiency or non-sufficiency of BIM size is its economical advisability, that is, the result of the comparison between the costs required for BIM creation, support at all stages of building life cycle and the advantages provided by the received informational and mathematical model. The fact that a lot of participants with different interests are involved in BIM creation process increases the complexity of the problem. In addition to this, it often happens so that ones are to bear the costs, and the others are to get the advantage.

Speaking formally, we have to solve a multi-attribute task with many contradicting criteria. In general cases, such tasks do not have an exact one-valued solution. In theory, a number of approaches to mathematical analysis of such situations is used to solve the task. As a rule, the approaches come down to trying to choose one most important criteria and optimize it. The other criteria are considered as a set of constraints.

In construction system engineering, there is a possibility to reject the analysis of contradicting criteria and go over to generalized, so called system engineering integrated criteria that describe the behavior of a system as a whole. The main idea is, that proper functioning of the system in fact results in reaching a balance of contradicting characteristics. 


\section{Organizational and technological reliability}

Organizational and technological reliability (OTR) is one of the important system engineering integrated criteria. This figure describes the probability of complex system object's reaching a goal. As opposed to classical reliability, here, in addition to system failures (capable to cause system breakdown) system disturbances (that impair life cycle figures but do not cause breakdown) are taken into account.

Construction companies operate in the stochastic environment. Being influenced by different random factors, course of the construction production objectively deviates from an established one. As a dynamic system the construction production demonstrates a strong probabilistic character. Not only the external factors, which influence the whole system, are probabilistic but also the behavior of each particular element in this system, beginning with human communities.

The main feature of construction systems, unlike technological systems, is their organizational character. In production process technical and social systems are united. The interaction between these two stochastic systems has not been taken into account neither in the produced organizational and technological documentation, nor in normative and reference basis (the construction norms and rules etc.). Failure to consider the stochastic character of the process of construction/reconstruction of manufacturing enterprises leads to insufficient adequacy and poor reliability of many organizational and technical, economical, management decisions, based on classical models.

The complexity of constructional technological processes, the complexity and the increasing numbers of constituent parts of organizational structures, the complexity of planning, economical and especially management decisions has led to the necessity of using entirely new, systematic approaches to the analysis of construction production as a system.

The solution to the problem of improving the organizational and technical reliability (OTR) holds big possibilities of improving the effectiveness of construction. The organizational and technical reliability can be viewed as the ability of organizational, technological and economical solutions to achieve the given objective of construction production in conditions of random shocks, usual in complex stochastic systems such as construction.

Man-machine (organizational, technological, management) systems, which include, not only technological but economical and social aspects, are characterized by a certain level of reliability, which decreases considerably with the complexity of the system. To define OTR of the system, the methods of the reliability theory, which is based on the analysis of distribution of random measures' sets - reliabilities of separate elements of a complex, are used. The likelihood of the index to achieve the projected size can be estimated with the help of these models and methods.

The increase of OTR can be achieved in different ways:

- by decreasing the size of factors, responsible for reliability of construction organization performance;

- by designing systems, functioning reliably in the presence of the above factors.

The realization of the first method is not always possible due to difficulties in determining the origins and causes of these factors. The second approach as well as the combination of the two are the most realistic ones.

In its broad meaning, OTR may be understood as a probability of receiving an economical effect. In this case, organizational and economical reliability (OER) will be the main figure describing building life cycle sustainability. 


\section{Conclusion}

Thus, the conditions of ecologically acceptable development of regional investment construction complex are: minimization of construction products are nature-based sustainable use of natural resources within the ecological life cycle; maximization of the generalized indicator of the ecological-economic efficiency of investment projects based on application of the best available technologies and environmental initiatives; modeling the equilibrium state, in which the increase of volume of performed works, manufactured products and the cost of ecological support of investment - construction activity does not violate the financial stability of economic entities.

The operation of construction companies as ecological - economic system necessitates evaluation of the effectiveness of activities based on ecological-economic analysis for structured components: an analysis of organizational aspects of environmental support productive activities; analysis of impact on components of the regional ecologicaleconomic system; analysis of the ecological and nature intensity of work; analysis of the use of resources, providing ecological support of investment-construction activities; analysis of the impact on economic and financial performance of enterprises; investment analysis $[2,3,5]$.

The practical significance of the study lies in the feasibility of using proposed scientific approaches, techniques in the practice of management, organization and planning of activity of the enterprises of investment-building complex, taking into account environmental aspects of development, in the activities of state administration bodies in the development of strategic plans and programs of development of investment and construction sector, relevant social and environmental priorities of the region development, the implementation of ecological-economic monitoring of construction industry.

The author believes that mainstreaming environmental knowledge in the regulation of investment and construction activities is possible through the expansion of the range of integration of ecoinstitut in the institutional environment of investment and construction sector and the institutional environment of ecological and economic regulation of investment and construction activities. The completeness of the integration processes is determined by the degree of greening of the totality of tools and methods of regulation of investment and construction activities.

\section{Summary}

The current building life cycle management system in the Russian Federation is a family of discrete subsystems that exist independently for different building life cycle stages. In this situation building reliability and sustainable functioning are out of the question. The implementation of a united information model (BIM-model) intended to describe building entire life cycle will allow to raise the sustainability, but this will happen only if goals and concerns of all participants of the project process are properly coordinated.

\section{References}

1. V.V. Talapov, BIM Technology. Essence and features of building information modeling introduction (DMK Press, Moscow, 2015)

2. A.V. Ginzburg, E.I. Nesterova, Vestnik MGSU, 5, 317 (2011)

3. A.V. Ginzburg, The automation of the organizational technological construction reliability designing (SEP RIA, Moscow, 1999)

4. A.V. Ginzburg, P.B. Kagan, CAD and graphics, 9, 32-34 (1999) 
5. A. Ginzburg, Processing Models In Organizational and Technological Design. In Abstract Volume, 14th International Conference on Computing in Civil and Building Engineering (14th ICCCBE), 518-519 (2012)

6. A. Ginzburg, Applied Mechanics and Materials, 405-408, 3352-3355 (2013)

7. A. Ginzburg, A. Khripushin, Applied Mechanics and Materials, 411-414, 2313-2316 (2013)

8. A. Ginzburg, A. Ryzhkova, Applied Mechanics and Materials, 672-674, 2221 (2014)

9. A. Ginzburg, A. Ryzhkova, International Journal of Applied Engineering Research, 10(21), 41828-41830 (2015)

10. A. Ginzburg, A. Ryzhkova, International Journal of Applied Engineering Research, 10(21), 42410-42411 (2015)

11. A. Ginzburg, A.Skiba, Applied Mechanics and Materials, 584-586, 507-511 (2014)

12. A. Ginzburg, S. Kachanov, International Journal of Applied Engineering Research, 11(3), 1660 (2016)

13. A. Ginzburg, S. Kachanov, International Journal of Applied Engineering Research, 10(20), 40869-40872 (2015)

14. A.A. Gusakov, System engineering in construction (Stroyizdat, Moscow, 1983)

15. S.A. Sinenko, Automation of organizational technological design in construction: The manual (Publishing company ASV, Moscow, 2002)

16. A.A. Volkov, S.N. Petrova, A.V. Ginzburg, Information management systems and data processing technologies in civil engineering (MGSU, Moscow, 2015)

17. A. Volkov, Applied Mechanics and Materials, 838-841, 2973 (2014)

18. A. Volkov, V. Chulkov, R. Kazaryan, R. Gazaryan, Applied Mechanics and Materials 584-586, 2685 (2014)

19. A. Volkov, Civil Engineering, 3, 54 (2012)

20. A. Volkov, A. Sedov, P. Chelyshkov, Applied Mechanics and Materials, 409-410, (2013) 630

21. V.V. Garyaeva, N.A. Garyaev, Computing in Civil and Building Engineering Proceedings International Conference, 1336 (2014) 